\title{
La nueva comunicación eclesial a la luz de los documentos magisteriales del lustro 1997-2002
}

\section{CARACTERÍSTICAS DE ESTE CAMBIO EPOCAL}

La información dejó de ser patrimonio de unos pocos. Podríamos afirmar que se encuentra al alcance de casi todos, lo que ha llevado a una relativa homogeneización de la sociedad. Esto, producto de la masificación de la misma información e inmediatez de los medios de comunicación y el gran desarrollo y penetración de la tecnología de las telecomunicaciones. La esencia de la novedad comunicacional ha traspasado fronteras geográficas, expandiéndose por el mundo a una velocidad inusitada. Encontramos fenómenos sociales semejantes en países tan distantes unos de otros como Corea y Chile, Sudáfrica o Filipinas. Esto se observa con claridad en los estratos juveniles, donde se pueden ver gustos, tendencias o motivaciones semejantes.

Vivimos en una aldea global - aldea virtual. La profecía de McLuhan en los años sesenta se ve superada por la realidad. Gracias a los beneficios de la tecnología cada día se acortan más las distancias y se derriban las fronteras que separan físicamente a las personas. Los jóvenes de hoy -y con mayor razón los del futuro- son más similares entre sí de lo que somos capaces de procesar. Esto mismo lleva a vivir procesos de cambio cada vez más rápidos. Si el así llamado "cambio generacional” duraba hasta la década de los ochenta, veinte años, hoy se habla de una nueva generación cada cinco años. Esto es tanto más visible en el campo de los computadores, donde los adelantos tecnológicos experimentan una renovación cada cinco meses.

\section{DE LA PIEZA DE GUARDAR AL SALÓN PRINCIPAL. TODO ES COMUNICACIÓN}

En esta época de cambios la comunicación es un elemento reivindicado por la sociedad en su conjunto. En el campo eclesial, ella ha experimentado una verdadera explosión (1). Esto mismo ha llevado a la Iglesia en los últimos lustros a

(1) El aumento explosivo de los medios de comunicación social lo señalan cientos de estadísticas sobre el tema. Basta como dato ilustrativo que el número de páginas web se acerca al billón, 
replantearse su trabajo y estrategia comunicacional, renovando sus métodos y la forma en que aborda este tema.

Entre las características de su cambio estratégico y su adaptación a las nuevas tecnologías, la Iglesia sigue entendiendo su misión como una tarea de evangelización de la cultura. Ella no se opone a muchos de los cambios epocales. Se inserta en el tiempo, vive en medio de él e intenta, con los criterios del Evangelio, transformarlo en un tiempo nuevo. A la luz del Evangelio, la Iglesia hace su aporte de discernimiento a la cultura, de lo que favorece y de lo que entorpece la vocación humana integral. En ese sentido, la vocación esencial de la Iglesia es el servicio concreto a los hombres y mujeres de todo tiempo.

La Iglesia se entiende en su política comunicacional como "excéntrica" (donde no tiene en sí su centro sino en Cristo y en el servicio a la humanidad) y "simpática" (sintoniza con todo lo humano, pues nada de lo humano le es ajeno). Esta autocomprensión la lleva a revalorar aspectos, desde la óptica comunicacional, de su ser comunitario, su cercanía a Cristo, su sentido "corporativo".

La Iglesia es ante todo una comunidad. En el sentido anterior, entiende su misión en correspondencia con su ser, de establecer vínculos con Dios y entre los hombres. Por lo tanto, uno de sus pilares es la unidad. Pero esta unidad no se confunde con uniformidad, sino que se plasma en una pluralidad, donde todos tienen la misma dignidad y cada miembro realiza su función y carisma. El ser comunión marca también el servicio eclesial de factor de unidad entre las personas, no solo al interior sino también al exterior de ella. La comunión y la participación en la vida de la Iglesia corresponden a su esencia y marcan su quehacer, en este caso el comunicacional, y su ser. Esto no es una simple "estrategia" pastoral dentro de otras sino que se desprende de su esencia y responde a su misión.

La tarea y la identidad más profunda de la Iglesia están en su cercanía con Cristo. La Iglesia busca trasparentar en su ser y en su actuar a Jesucristo. Muchas de sus tareas más urgentes se orientan por ese camino. Su servicio al mundo no es cualquier servicio: Es eclesial y es cristiano, evangélico.

La imagen corporativa (del cuerpo) de una institución se puede entender como la proyección exterior de su identidad. Esta no es una mera proyección publicitaria hacia el exterior, sino que supone y parte de una identidad o conciencia interna, la cual se transmite hacia fuera determinando su mensaje pastoral. Cuando la Iglesia anuncia a Cristo se anuncia como comunidad y participación comunitaria en Él. La coincidencia entre imagen externa e identidad interna resulta por ello un desafío y cuestionamiento constante para la misma misión de la Iglesia, que busca comunicarse y comunicar la verdad, que es Cristo. Por lo tanto, la tarea de las comunicaciones en la Iglesia es contribuir a que esta identidad plasme en esa dimensión y desde esa perspectiva el corazón de todos los hombres.

donde el ítem "religión" es el cuarto o quinto más visitado en los grandes buscadores de Internet, tras pornografía, música y deportes. En el campo de la televisión, el aumento de canales con programación religiosa resulta igualmente notable. 


\section{LAS NUEVAS ACTITUDES ECLESIALES}

La nueva actitud eclesial ante los medios de comunicación social se perfila claramente en la política comunicacional adoptada por el magisterio en el último lustro. Esta nueva actitud eclesial la encontramos plasmada en los siguientes documentos:

a. Presencia amiga para quien busca al Padre (Mensaje del Santo Padre para la 33a Jornada Mundial de Comunicación Social (1999): "Los mass-media: Presencia amiga para quien busca al Padre"

b. Renovación del anuncio de Cristo en los Medios de Comunicación Social. Mensaje del Santo Padre para la $34^{\mathrm{a}}$ Jornada Mundial de Comunicación Social (2000): “Anunciar a Cristo en los Medios de Comunicación Social al alba del Tercer Milenio"

c. Desafíos de la Era de Comunicación Global. Mensaje del Santo Padre para la 35 a Jornada Mundial de Comunicación Social (2001): "Proclamar desde los terrados: el Evangelio en la Era de la Comunicación Global”

d. Mensaje del Santo Padre para la 36 Jornada Mundial de Comunicación Social (2002): "Internet: un nuevo foro para la proclamación del Evangelio"

A estos documentos se suman otros que los complementan en su contenido:

a. Preocupación por las personas que trabajan en los medios de comunicación social. Junio de 2000, Jornada Mundial de Comunicación Social, Jubileo de los Periodistas. John P. Foley, Ética en las Comunicaciones Sociales.

b. Necesidad de formación en el área de los medios de comunicación social. Orientaciones sobre la formación de los futuros sacerdotes para el uso de los instrumentos de la Comunicación social. Congregación para la Educación Católica.

c. "Un nuevo ethos. Ética en Internet". 22 de febrero 2002, John P. Foley del Pontificio Consejo para las comunicaciones Sociales.

\section{HACIA UNA NUEVA FORMA DE COMUNICAR. ACENTOS ECLESIALES EN LOS ÚLTIMOS DOCUMENTOS DEL MAGISTERIO}

\subsection{Los Medios de Comunicación Social: una mano amiga para la transmisión del Evangelio}

El magisterio, sobre todo bajo el pontificado de Juan Pablo II, ha buscado romper con una política de desconfianza con relación a los medios, que no logra otra cosa que alejar a la Iglesia de estos y con ello separarla de la sociedad. Cooperación significa mayor entendimiento, despejar las desconfianzas y recelos. Para ello, la Iglesia aporta su cultura de sabiduría que puede salvar a la cultura de información de los mass-media de convertirse en una acumulación de hechos sin sentido. Aporta una cultura de alegría que busca salvar la cultura de entretenimiento de los medios de convertirse en una fuga desalmada de la verdad y la responsabilidad. A su vez, el 
magisterio entiende que los medios pueden ayudar a la Iglesia a comprender mejor cómo comunicar con la gente de forma atractiva y que a la vez deleite (2).

\subsection{Anunciar a Cristo en los medios de comunicación social al alba del Tercer Milenio}

El aprovechamiento de los medios de comunicación social no excluye la proclamación personal y directa del mensaje evangélico, en la que la persona comparte con otra su fe en el Resucitado. Junto con subrayar esta dimensión apostólica, los documentos magisteriales de los últimos lustros subrayan la proclamación de la palabra en y a través de los medios de comunicación social. "La Iglesia se sentiría culpable ante el Señor si no utilizara estos poderosos medios" (3).

Los documentos del magisterio insisten en el impacto de los medios sobre el mundo actual. El surgimiento de la sociedad de la información es una verdadera revolución cultural, que transforma a los medios en "el primer Areópago de nuestra época”, en el cual se intercambian constantemente ideas y valores (4).

A través de los medios la gente entra en contacto con personas y acontecimientos, y se forma su opinión sobre el mundo en el que vive. Incluso ahí se configura su modo de entender el sentido de la vida. Para muchos su propia experiencia vital es en gran medida una prolongación de la experiencia de los medios de comunicación (5). El anuncio de Cristo, por tanto, debe formar parte de esta experiencia.

\section{3. "Proclamar desde los terrados": el Evangelio en la Era de la Comunicación Global}

Los documentos magisteriales no son ajenos al extraordinario desarrollo de los medios de comunicación en los últimos lustros y concretamente del auge explosivo de Internet. Ellos toman consciencia de que día a día la red de las comunicaciones globales se extiende y crece de forma más compleja, ejerciendo visiblemente una mayor influencia sobre la cultura y su divulgación.

En el pasado los medios informaban sobre los acontecimientos, ahora, con frecuencia, son las necesidades de los medios las que dan forma a los acontecimientos. De este modo la interacción entre la realidad y los medios se ha hecho cada vez más compleja dando lugar a un profundo fenómeno ambivalente. Por una parte se puede deformar la distinción entre verdad e ilusión; pero por otra, es posible crear oportunidades sin precedentes para hacer que la verdad sea mucho más accesible a muchas más personas (6).

(2) Cfr. Mensaje para la 33a Jornada Mundial para las comunicaciones sociales. "Los mass-media: presencia amiga para quien busca al Padre", 1999

(3) Papa Pablo VI, Evangelii Nuntiandi, 45

(4) Redemptoris Missio, 37; mensaje para la 34a Jornada Mundial para las comunicaciones sociales. "Anunciar a Cristo en los medios de comunicación social al alba del tercer milenio", 2000

(5) Cf. Pontificio Consejo para las Comunicaciones Sociales, Aetatis Novae, 2.

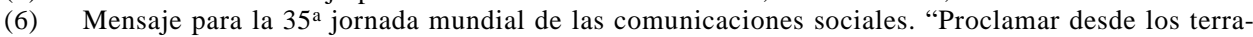
dos": el evangelio en la era de la comunicación global", 2001 
El documento magisterial sobre el evangelio en la era de las comunicaciones constata la dificultad del mensaje religioso en un mundo aparentemente ajeno a él: "A veces el mundo de los medios puede parecer indiferente e incluso hostil a la fe y la moral cristiana" (7). En parte esto sucede porque la cultura mediática se ha ido penetrando progresivamente de un sentido típicamente postmoderno donde la única verdad absoluta admitida es la inexistencia de la verdad absoluta o, en caso de que esta existiese, sería inaccesible a la razón humana y por lo tanto irrelevante. Con una tal perspectiva, lo que acontece no es la verdad sino "el relato"; si algo es noticia digna o entretenida, la tentación de apartar las consideraciones de la verdad se hace casi siempre irresistible. "Como resultado, el mundo de los medios puede, algunas veces, parecer un ambiente tan poco propicio para la evangelización como el mundo pagano en tiempos de los Apóstoles" (8).

Sin embargo, del mismo modo que el mundo de los medios puede, a veces, dar la impresión de estar reñido con el mensaje cristiano, "este también ofrece oportunidades únicas para proclamar, a la entera familia humana, la verdad salvífica de Cristo" (9). El magisterio insiste en la necesidad de un activo e imaginativo compromiso ante los medios por parte de la Iglesia: "Los católicos no tendrían que sentir temor de abrir las puertas de la comunicación social a Cristo, de forma que la Buena Nueva pueda ser oída desde los terrados del mundo" (10).

\subsection{Los nuevos foros para la proclamación del Evangelio}

La primera convicción de los documentos magisteriales es que no hay medio que no sea apto para la evangelización. Por ello, la Iglesia afronta esta nueva era con realismo y confianza. El auge de Internet, por ejemplo, da cuenta de una explosión de la información de consecuencias inimaginables.

La misma red es utilizada prácticamente por todas las comunidades religiosas y la Iglesia, en su conjunto, ha dado cuenta de un uso eficiente de ella. La experiencia demuestra que, a través de ella, se hace posible un encuentro inicial con el mensaje cristiano, especialmente entre los jóvenes, que se dirigen cada vez más al mundo del ciberespacio como una ventana abierta al mundo

Internet también puede facilitar el tipo de seguimiento que requiere la evangelización. Especialmente en una cultura que carece de bases firmes, la vida cristiana requiere una instrucción y una catequesis continuas, y esta es tal vez el área en que Internet puede brindar una excelente ayuda. Basta ver que un porcentaje no menor de páginas web está dedicado a temas religiosos. En ella encontramos una inagotable fuente de información, documentación y educación sobre la Iglesia, su historia y

(7) Cf. ídem

(8) Mensaje para la $35^{\text {a }}$ jornada mundial de las comunicaciones sociales. "Proclamar desde los terrados: el evangelio en la era de la comunicación global", 2001, 3.

(9) Cf. ídem. Tengamos en cuenta, por ejemplo, los programas vía satélite de ceremonias religiosas que, con frecuencia, alcanzan una audiencia enorme, o las buenas posibilidades que ofrece Internet para difundir la información y enseñanza religiosas sobrepasando obstáculos y fronteras. Una audiencia tan vasta habría sido imposible de imaginar hasta hace unos decenios para la predicación del Evangelio.

(10) Cf. ídem, 3. 
su tradición, su doctrina y su compromiso en todos los campos en todas las partes del mundo.

Ahora bien, los documentos eclesiales son conscientes de que estos foros no suplen la profunda experiencia de Dios que solo puede brindar la vida litúrgica y sacramental. Pero también la Iglesia busca acentuar que esto puede proporcionar un suplemento y un apoyo únicos para preparar el encuentro con Cristo en la comunidad y sostener a los nuevos creyentes en el camino de fe que comienza entonces (11).

\section{NUEVOS DESAFÍOS Y PREGUNTAS ABIERTAS ANTE LOS NUEVOS MEDIOS DE COMUNICACIÓN SOCIAL}

El magisterio, junto con apoyar el uso de los medios de comunicación social como Internet, plantea algunas interrogantes que son válidas para toda la sociedad. La esencia de Internet consiste en suministrar un flujo casi continuo de información, gran parte de la cual pasa en un momento. En una cultura que se alimenta de lo efímero puede existir fácilmente el riesgo de considerar que lo que importa son los datos, más que los valores.

Internet ofrece amplios conocimientos, pero no enseña valores. Incluso se pueden constatar modos degradantes y perjudiciales en su uso, los que constituyen un desafío para toda la sociedad.

Además, Internet redefine radicalmente la relación psicológica de la persona con el tiempo y el espacio. La atención se concentra en lo que es tangible, útil e inmediatamente asequible; puede faltar el estímulo para profundizar más el pensamiento y la reflexión. Se presenta entonces como desafío "la necesidad vital de tiempo y serenidad interior para ponderar y examinar la vida y sus misterios, y para llegar gradualmente a un dominio maduro de sí mismos y del mundo que los rodea" (12).

Ahora bien, el entendimiento de la realidad humana, del devenir histórico y la sabiduría con que se la contempla son fruto de una mirada contemplativa sobre el mundo, y no derivan de una mera acumulación de datos, por interesantes que sean. De ahí que el enfoque eclesial ante los medios siempre será distinta al que puedan tener otros organismos sociales.

El magisterio es consciente de las bondades de los nuevos medios de comunicación social, pero a su vez advierte sobre los potenciales peligros que se desprenden de su uso irresponsable. Internet se presenta como un foro en el que prácticamente todo se acepta y casi nada perdura, favorece una forma relativista de pensar y a veces fomenta la evasión de la responsabilidad y del compromiso personal (13).

En este mismo contexto, se hace necesario reflexionar sobre la forma de cultivar la sabiduría que no viene precisamente de la información, sino de la visión

(11) Estudios realizados por el CEP señalan una tendencia juvenil creciente hacia la configuración de grupos pequeños y la búsqueda del encuentro personal. También ha aumentado la exigencia de los alumnos en las universidades por una mayor presencia de los profesores, al revés de lo que podría pensarse a raíz del aumento de los cursos virtuales

(12) Mensaje para la $36^{a}$ jornada mundial de las comunicaciones sociales. "Internet: un nuevo foro para la proclamación del evangelio", 2002, 4.

(13) Cf. ídem, 5 
profunda; la que comprende la diferencia entre lo correcto y lo incorrecto, y sostiene la escala de valores que surge de esta diferencia.

Junto con plantear interrogantes, se subraya en todos los documentos los aspectos positivos de este nuevo medio. El hecho de que a través de Internet la gente multiplique sus contactos de modos hasta ahora impensables abre maravillosas posibilidades de difundir el Evangelio. Pero también es verdad que las relaciones establecidas mediante la electrónica jamás pueden tomar el lugar de los contactos humanos directos, necesarios para una auténtica evangelización, pues la evangelización depende siempre del testimonio personal del que ha sido enviado a evangelizar (cf. $R m$ 10, 14-15). Un desafío inmediato será la forma como guíe la Iglesia, desde el tipo de contacto que permite Internet, a la comunicación más profunda que exige el anuncio cristiano y cómo entablamos el primer contacto y el intercambio de información que permite Internet.

La Iglesia se hace cargo de otros desafíos que presenta la red como son el agravamiento de las desigualdades existentes al ensanchar la brecha de la información y las comunicaciones; o el hacer de esto un instrumento a la causa de la paz; de fomento de una cultura del diálogo, de la participación, de la solidaridad y de la reconciliación.

Por último, los documentos subrayan el impacto de imágenes que surge de Internet. "Internet produce un número incalculable de imágenes que aparecen en millones de pantallas de ordenadores en todo el planeta. En esta galaxia de imágenes y sonidos, puede y debe aparecer el rostro de Cristo y escucharse su voz, que es la finalidad de toda evangelización. Solo eso convertirá a Internet en un espacio auténticamente humano, puesto que si no hay lugar para Cristo, tampoco hay lugar para el hombre" (14).

\section{ALGUNOS PUNTOS PARA CONSIDERAR EN LA POLÍTICA COMUNI- CACIONAL ECLESIAL}

\subsection{Todo en la Iglesia es comunicación}

Un estudio realizado por el Instituto de Estudios Mediales de la Pontificia Universidad Católica en enero de 2000 muestra que la gente común no distingue entre los distintos estamentos eclesiales (15). Para la mayoría la idea de "Iglesia" es una sola, sin distingo de estamentos como obispos, párrocos, agentes pastorales o áreas de trabajo. La idea de imagen corporativa es cada vez más fuerte en la opinión pública, influenciada sin duda por las grandes instituciones públicas o empresas de gran envergadura mundial De ahí que se pueda afirmar que nada escapa al ámbito comunicacional, dado que la percepción de la opinión pública es que "todo" en ella

(14) Mensaje para la $36^{\mathrm{a}}$ jornada mundial de las comunicaciones sociales. "Internet: un nuevo foro para la proclamación del evangelio", 2002, 6.

(15) Cf. Estudio Nacional Iglesia. Conferencia episcopal de Chile. 2000. DESUC. Pontificia Universidad Católica de Chile. 
habla, cuando cualquiera de sus integrantes habla. Esto influye en la recepción de los comunicados y en el orden de la Iglesia.

Este aspecto, novedoso y creciente en los últimos años, abre la necesidad de una mejor "gestión de marca e imagen corporativa" utilizando una expresión propia del campo mercantil. "Los productores fabrican productos; los consumidores compran marcas", se podría resumir esta nueva actitud ante la idea de Iglesia.

\subsection{Reapropiación versus identificación}

Desde una perspectiva comunicacional resulta importante ayudar a las personas a reconocer y asumir su realidad personal, más que a forzarlos a identificarse con lo que nosotros definimos como "aspiracional". Es decir, es mucho más "rentable" desde este punto de vista mostrar la realidad tal como es y ayudar a comprenderla, antes que insistir únicamente en la meta última de todo cristiano, siempre necesaria, pero cuyo planteamiento unilateral puede ser fuente de frustración y alejamiento de la Iglesia, antes que de acercamiento a ella (16).

Se ha producido en ese sentido un "rechazo a la figura perfecta", presentada por los medios hasta hace unos años y explotada por la propaganda. Ante ella va tomando relevancia la vida de personas normales, con las que el espectador se pueda identificar más fácilmente. El mensaje eclesial no puede inducir a complejos de inferioridad, sino que debe acentuar la bondad inserta en la vida de todos los hombres.

\subsection{Combinar el anhelo para conseguir metas altas y la presentación del camino por recorrer}

Los documentos del magisterio están conscientes de la dificultad que supone una sobre acentuación de la importancia de la fe para la vida, sin considerar la realidad vital de las personas que lo reciben. Esto puede, paradójicamente, ser más perjudicial que beneficioso, siendo que lo único que se lograría es recordarle a las personas lo difícil que es lograr alcanzar la meta cristiana o lo lejos que están de ella. La fe es seria, pero no grave (17).

\subsection{Pragmatismo: la palabra clave}

El cambio epocal que hemos querido describir anteriormente nos habla de una valoración creciente de las soluciones concretas a los problemas sociales y comunitarios, antes que a los grandes discursos a los que nos tenían acostumbrado los medios hasta hace algunos lustros. Se prefiere la información clara, precisa y

(16) El camino es tan importante como la meta. Como ejemplo de esto basta ver el auge de comerciales con imágenes normales, personas de la calle, con las cuales el espectador se siente más identificado. Ej.: "No me muestres publicidad que me sugiera que si uso tal producto voy a ser, verme o convertirme en esa persona o familia perfecta que me estás mostrando. Mi realidad no es esa".

(17) Como dijo un joven en un sondeo de una conocida marca de bebidas: "Trátame con respeto, como alguien que tiene inteligencia y sentido del humor. Demuéstrame que los héroes también se equivocan". Un buen ejemplo de esto es la publicación de casos ejemplares. 
concisa antes que la divagación reflexiva, por interesante y sugerente que sea. En ese sentido, se hace necesario en toda labor pastoral comunicacional acompañar a la palabra, el gesto adecuado. La importancia de lo testimonial hoy en día es crucial para la comprehensión plena del mensaje evangélico. Expresiones como "consecuencia de vida", "radicalidad en la entrega", "honestidad", tan en boga, se encuentra detrás de esta tendencia. Esto mismo se extiende a la imagen como puente comunicacional esencial, la que adquiere una importancia enorme, mayor que cualquier discurso. Toda palabra debe ir acompañada de un gesto adecuado que la ilustre, enriquezca y explique. Ejemplos serían valores como la solidaridad, la caridad, el derecho a la vida. De alguna manera se ha hecho realidad aquí la expresión de los "intereses reales de la gente", que cambió la forma de hacer política en Chile.

\subsection{Un discurso sin conflicto}

Lo expuesto anteriormente nos lleva a otra conclusión del nuevo paradigma comunicacional de este tiempo: el discurso religioso y eclesial debe iluminar, indicar caminos, sugerir, antes que obligar o forzar. Podemos hablar de la búsqueda de un discurso desconflictuado que, antes que cuestionar o provocar rechazo en la gente, acentúe sus aspectos positivos y desde allí proclame la palabra del Evangelio. El argumento de autoridad podrá presentarse en una primera instancia, pero pierde validez ante un auditor escéptico y que cuenta con su propia mirada de la realidad. Solo la convicción interior que se gana de la presentación convincente de la palabra cristiana es el que se termina por imponer.

\subsection{Potenciar una identidad corporativa común sobre la base de orientaciones comunes}

El esfuerzo comunicacional -evangelizador en último término- estará entonces dirigido a ampliar el universo de identidad de cada una de las iniciativas de Iglesia. Se trata de darse a conocer sin temores, sobre todo ante el peligro de que se deslaven las iniciativas de Iglesia en mera filantropía y pierdan su consistencia evangélica.

Solo a través de una manifestación convencida del Evangelio se fortalece el sentimiento de pertenencia a un cuerpo mayor: la Iglesia, llamada a cumplir la misión encomendada por Jesucristo. En ese sentido, y llevando esto al plano meramente práctico, la antigua distinción entre comunicación externa e interna se ve superada por una presentación de una imagen orgánica de la Iglesia, en la cual la identidad de cuerpo aparece como la única existente. Al ser un todo comunicacional, lo que aparentemente se presenta en el plano interno es también comunicación externa. Ellas son dos caras de una misma moneda. Junto a esto, se debe consolidar y ampliar el posicionamiento eclesial alcanzado, el cual, al menos en la realidad chilena, es positivo.

Eso sí, aparecen elementos que representan riesgos que llevarían a perder posiciones u otros donde la posición eclesial aparece como neutra, indefinida o desconocida. Esto exige esfuerzos de información, aclaración y aun de definiciones, sobre la base del evangelio y el magisterio. 
Una forma concreta de conservar y aumentar la posición eclesial en el espectro social sería el transformar actividades institucionales en fuentes de comunicación. Vale decir, no ser elemento pasivo dentro del esquema noticioso, sino crearla.

\subsection{Expectativa de una palabra orientadora}

El galopante cambio social de los últimos lustros ha llevado a la sociedad a la búsqueda de voces clarificadoras de los fenómenos sociales. En el terreno práctico, se percibe un notable aumento de charlas sobre valores, búsqueda de columnas de opinión en los periódicos y revistas, foros y seminarios. Se percibe como provechoso para la Iglesia el uso de estas instancias laicales.

A pesar de lo que puedan pensar algunos sectores, el espectro de medios en la realidad chilena es relativamente abierta a la Iglesia, lo que no significa que esté abierta a su postura ni que se sienta obligada a defender sus posiciones. Eso sí, se la considera un interlocutor necesario, serio y válido, cualquiera sea el tema de relevancia social que se toque.

La suspicacia y beligerancia ha sido despertada en muchas ocasiones desde los centros eclesiales y no al revés. La necesidad de una palabra orientadora crece en la medida en que los fenómenos noticiosos se vuelven más complejos. Se sabe por qué suceden las cosas, lo que se busca es el trasfondo de ellas (18). Estos efectos o externalidades son de alto valor estratégico para la Iglesia, por lo que merecen ser potenciados comunicacionalmente.

Otro tanto sucede en el plano de los valores, donde su opinión es buscada. Esto obliga a un conocimiento de la realidad, el desarrollo y evolución de los fenómenos sociales y a una cierta anticipación de los grandes temas de la coyuntura, sobre los que tanto el pueblo católico como la opinión pública nacional piden y esperan un pronunciamiento eclesial. Prever la agenda de intervenciones públicas, su contenido y oportunidad, es una de las principales acciones de posicionamiento público y, por tanto, de la formación de la imagen.

Todo esto apunta a potenciar una identidad/imagen corporativa sólida, atractiva y coherente con un proyecto de sociedad fundado en los valores del evangelio. Los medios de comunicación social se entienden con la Iglesia sin más y la presentan como un todo orgánico sin mayores distingos, los cuales solo confunden a la opinión pública.

\subsection{Necesidad de formación permanente}

Los documentos magisteriales de los últimos años acentúan la necesidad de una formación permanente del clero y agentes pastorales en el área de las comunicaciones. No sirven las improvisaciones en este campo. Cada comunidad, colegio e institución de Iglesia requiere un equipo de opinión pública. La opinión pública, motivada por los mismos medios de comunicación social esperan una toma de posi-

(18) Un buen ejemplo de esto sería el atentado terrorista a las torres gemelas en Nueva York. Se esperaba de la Iglesia una palabra de consuelo y esperanza. 
ción eclesial no solo ante los grandes temas de la contingencia nacional, sino que incluso ante temas aparentemente insignificantes (19).

\subsection{Gestión de crisis}

Los rápidos cambios culturales han producido un fenómeno nuevo. La imprevisibilidad de los fenómenos sociales. La estructura de sociedad lineal, ordenada y previsible en sus cambios y desarrollo no existe más. Vivimos en una sociedad que debe acostumbrarse a las crisis. Es más, estas son parte del devenir social. Los medios de comunicación social suscitan estas mismas crisis o incluso las provocan al acentuar o desatender determinados procesos sociales. Su tendencia a polarizar la realidad para crear la noticia provoca situaciones de crisis, de mayor o menor envergadura, dentro del tejido social. El problema no radica en la crisis sino en su gestión.

\section{CRITERIOS COMUNICACIONALES COMUNES}

De los documentos del magisterio se desprenden una serie de criterios comunicacionales que pueden ser aplicados a la gestión comunicacional eclesial. Por de pronto, el común denominador de todos los documentos está en el anuncio de la buena nueva como la gran noticia para todos los hombres. La Iglesia y su mensaje, al ser ella misma mensaje, es siempre acontecimiento noticioso. De ahí que un criterio es el de generar la noticia y no ser solo parte de ella. Podemos hablar de un criterio eclesial proactivo, interviniendo en todas las conversaciones relevantes del diálogo social que graviten en el cumplimiento de su misión.

Esto nos debe llevar a desterrar la suspicacia y la desconfianza ante los medios de comunicación social. Para ello se debe renovar la actitud de servicio con que se enfrenta el diálogo con los medios de comunicación social, anticipándose a las noticias de Iglesia, ofreciendo dilucidar dudas y despejar incógnitas. Esto, a partir del conocimiento de lo que sucede en los principales públicos de interés. Para ello, la Iglesia debe buscar posicionarse como actor relevante y con opinión en dichas conversaciones. Adelantarse a la noticia no es solo ser parte de ella, sino es crearla. Para que esto resulte eficaz, se deben aprovechar mejor las instancias y los canales sociales ya existentes.

(19) Todos los documentos acentúan este aspecto. Valgan las siguientes citas: "Las escuelas y otras instituciones y programas educativos para niños y adultos deberían proporcionar formación con vistas al uso inteligente de Internet como parte de una educación completa en los medios de comunicación que no solo incluye la capacitación técnica -primeras nociones de ordenador y otros conocimientos-, sino también la adquisición de una capacidad para evaluar de modo informado y sagaz los contenidos". Pontificio Consejo para las Comunicaciones Sociales. "Ética en Internet", 2002, 15: "Hoy todos necesitan alguna forma de formación permanente acerca de los medios de comunicación, sea mediante el estudio personal, sea mediante la participación en un programa organizado, sea con ambos. La educación en el uso de los medios de comunicación, más que enseñar algo acerca de las técnicas, ayuda a la gente a formarse criterios de buen gusto y juicios morales verdaderos, que constituyen un aspecto de la formación de la conciencia”. Ética en las comunicaciones sociales. Pontificio Consejo para mas Comunicaciones, 2000, 15. 
Junto a esto, los documentos están conscientes del liderazgo social, inherente a la realidad de comunidad de la Iglesia. Los liderazgos institucionales se ordenan bajo un proyecto común, lo que contribuye a la credibilidad del proyecto mismo y a la posibilidad de generar cierta mística. Esto se da tanto al interior de la Iglesia como al nivel de la opinión pública. La comunicación de este concepto pasa por enfatizar la proyección pública del liderazgo eclesial.

Para que esto sea eficaz y fecundo se requiere reforzar la calidad de institución de servicio, lo que no siempre es percibido por la opinión pública, a pesar de la enorme cantidad de organizaciones sociales de la Iglesia. La opinión pública no siempre percibe como inherente a la Iglesia o parte de ella los múltiples servicios que presta la Iglesia en todo orden de cosas. Este concepto define una propuesta institucional basada en la creación de una identidad/imagen centrada en la existencia de un proyecto de vida humana que se proyecta en la sociedad, fundado en el evangelio de Cristo, con contenidos y valores explícitos. Pero también con acciones múltiples en diferentes dimensiones de la sociedad. Estas dimensiones son múltiples, destacándose la defensa y promoción de los derechos humanos, la asistencia de los más pobres, la educación, la salud y la cultura en sus múltiples expresiones.

Para que las actividades comunicacionales encuentren un desarrollo orgánico y armonioso se exige una administración eficaz, ejercida con un claro y fuerte liderazgo, integrada por personas con una decidida adhesión a sus contenidos y principios, y poseedoras de una gran vocación de servicio a las personas y al país (20).

Como último criterio comunicacional, el magisterio insiste en la necesidad de reafirmar el carácter meramente religioso de la institución y que su vinculación con los grandes temas de la sociedad se funda en su misión de ordenar la acción humana hacia lo trascendente, que es Dios, por el camino señalado por Jesucristo en el evangelio. De ahí la necesidad de impregnar toda actividad con este cariz, cuidando su identidad corporativa.

\section{ESTRUCTURA BÁSICA DEL DISCURSO ECLESIAL}

Si bien los documentos magisteriales no ahondan en aspectos técnicos del discurso comunicacional, de todos ellos se puede descubrir una sugerencia básica de estructura, la que corresponde por lo demás a su esencia. El discurso, entendido no como una declaración sino más bien como las características de las palabras y los gestos, asume la triple misión de acoger, guiar y proteger.

\section{La iglesia acoge}

Todo discurso comunicacional debe cuidar de presentar siempre una Iglesia acogedora, dialogante, que quiere servir al país, que posee una sabiduría en el tema

(20) En otros términos, se trata de explicitar que las múltiples acciones de servicio y asistencia que brinda la Iglesia a la sociedad chilena abarcan un enorme segmento de la población del país y una movilización de recursos humanos, materiales y económicos que la sitúan a la cabeza de las instituciones sociales que operan sin aportes fiscales. 
del que habla, la que es también fruto de su conocimiento bimilenario. Para ello se debe preocupar de utilizar lenguajes y tonos tan propositivos y sugerentes, como claros y bien argumentados. Ese discurso evitará los lenguajes, tonos y gestos autoritarios, que se perciban impositivos, los que, como dijimos, en principio pueden despertar temor, pero finalmente suscitan rebeldía. Para ello se tendrá especial cuidado de ser respetuosos y delicados con quienes están en dificultades, y con quienes piensan distinto. La verdad misma exige pedagogía en su presentación así como un crecimiento paulatino en la realidad en que se anuncia. El extremar el cuidado del lenguaje en este sentido no atenta contra ella ni la parcela, sino que exige mayor inteligencia y creatividad para que resulte convincente y atractiva.

\section{La Iglesia guía}

Junto al acogimiento como criterio comunicacional se encuentra el aspecto guiador de la Iglesia. Para ello la sugerencia magisterial aconseja, en un primer nivel del diálogo comunicacional, la utilización de argumentos antropológicos, con conciencia de encontrarnos en un contexto social pluralista y con deficiente formación religiosa, aun de los católicos. Y desde estos avanzar pedagógicamente a la dimensión religiosa. Especial cuidado en el uso del argumento natural, que a muchos cuesta comprender y lo confunden con otros conceptos. Además, se debe presentar siempre una posición constructiva de la Iglesia respecto de temas controvertidos y ofrecer caminos de solución.

La percepción de Iglesia maestra lleva a una relación compleja y dificultosa con la opinión pública de lejanía e imposición. Para que este efecto se aminore, resulta aconsejable equilibrar la transmisión del mensaje evangélico con la utilización de ejemplos y testimonios de vida, así como la presencia de laicos debidamente formados.

\section{La Iglesia protege}

El foco de preocupación de la Iglesia es servir a los seres humanos, en particular a los que sufren. Para ello la Iglesia ofrece variados caminos en donde se demuestra esta preocupación. Hay que mencionar lo que la Iglesia hace, a través de algunas de sus múltiples expresiones, en el campo del tema que trate su palabra. Aquí cabe señalar especialmente su inmensa labor en el ámbito de la pobreza, educación, salud, etc. Para que esto resulte eficaz, conviene perfilar el grupo al que se dirige el mensaje. La acción comunicacional, en cualquiera de sus dimensiones, necesita saber cuáles son sus destinatarios para seleccionar la forma y contenido de sus acciones. Cumplir con tal propósito es requisito indispensable para lograr la eficacia deseada. Ayuda a esto el tomar conciencia de que los públicos relevantes son por naturaleza dinámicos y se constituyen en función de la necesidad y de la situación comunicacional de cada momento. Importante entonces resulta el saber siempre a quiénes nos dirigimos y por qué. Como públicos prioritarios de la Iglesia encontramos los jóvenes, las familias, los no creyentes de buena voluntad. Todos estos se encuentran dentro del ámbito de protección de la Iglesia, en el sentido de que el mensaje evangélico los debe considerar siempre como interlocutores, cualquiera sea el mensaje o discurso que se comunique. 


\title{
RESUMEN
}

Las afirmaciones sobre un cambio epocal a raíz de la explosión de los medios de comunicación no exageran. El fenómeno descrito por el teórico de las comunicaciones McLuhan sobre la "aldea global" hace algunos decenios se hacen día a día realidad. No nos extraña poder ver el mundial de fútbol en Corea, los juegos olímpicos en Suiza o que el Papa le hable a mil millones de personas simultáneamente en su mensaje de Navidad. Podemos trasladar una biblioteca entera de un país a otro o "bajarla" de Internet en cosa de minutos. Los cambios comunicacionales son de tal envergadura que se habla de una revolución como la que experimentó la humanidad a fines del siglo XIX con la revolución industrial. Y eso que nos encontramos recién en sus comienzos (22).

Los continuos cambios en este campo de las ciencias tan gravitante ha gatillado una serie de documentos del magisterio, donde la Iglesia ha tomado postura ante ellos y dado valiosas orientaciones sobre su uso y validez. Sobre estos aspectos trataremos en las próximas páginas.

\begin{abstract}
The assertions about an era change caused by the explosion of the media, are not an exaggeration. The phenomenon described some decades ago by the media theorist McLuhan on the 'global village' are a reality today. We are no longer surprised to watch the football world cup in Korea, the Olympic games in Switzerland or the Pope giving his Christmas message to millions of people simultaneously. In the Internet, we can 'download' whole libraries from other countries in a matter of minutes. The changes in communications are such, that they are said to match the revolution the humanity went through at the end of the XIX century with the Industrial Revolution. Nevertheless, these changes are only in their early stages. The ongoing shifts in this field have encouraged the Magisterium to publish a series of documents. In them, the Church has adopted a position and has given valuable orientations on their use and validity. These issues will be dealt with in this article.
\end{abstract}

(22) Cf. Consejo Pontificio para las Comunicaciones Sociales, instrucción pastoral Aetatis novae sobre las comunicaciones sociales, con ocasión del vigésimo aniversario de la Communio et progressio, n. 4. "El cambio que hoy se ha producido en las comunicaciones supone, más que una simple revolución técnica, la completa transformación de aquello a través de lo cual la humanidad capta el mundo que le rodea y que la percepción verifica y expresa. El constante ofrecimiento de imágenes e ideas así como su rápida transmisión, realizada de un continente a otro, tienen consecuencias, positivas y negativas al mismo tiempo, sobre el desarrollo psicológico, moral y social de las personas, la estructura y el funcionamiento de las sociedades, el intercambio de una cultura con otra, la percepción y la transmisión de los valores, las ideas del mundo, las ideologías y las convicciones religiosas". 